\title{
Time window-of-opportunity strategies for oil spill planning and response*
}

\author{
Atle B. Nordvik \\ Environmental Marine Technology \& Associates, 2230 Central Avenue, Vienna, \\ VA 22182, USA
}

Abstract: This paper presents an integrated scientific and engineering strategy to improve and bring planning and decision-making for marine oil spill response to a higher level of knowledge. The most efficient, environmentally preferred, and cost effective spill response is dependent on the following factors: chemistry of the spilled product, quantity, location, response time, environmental conditions, and effectiveness of available response technologies at various degrees of oil weathering.

Time windows is a highly targeted process, in which the selection of response technologies will be more efficient, cost effective, technically correct, and environmentally sensitive and appropriate. The strategy integrates dynamic oil weathering data and performance effectiveness data for oil spill response technologies derived from laboratory, mesoscale, and experimental field studies. Performance data has been developed from a wide range of viscosities of different weathering stages of transported oils into a dynamic oil weathering database to identify and estimate time periods, called 'technology windows-of-opportunity.' In these windows, specific response methods, technologies, equipment, or products are more effective during clean-up operations for specific oils. The data bases represent the state of the art for response technologies and research in oil spill response.

The strategy provides a standard foundation for rapid and cost effective oil spill response decision-making, and is intended for use by local, state, federal agencies, response planners, clean up organizations (responders), insurance companies, tanker owners, and transporters. It provides policy, planners and decision-makers with a scientifically based and documented 'tool' in oil spill response that has not been available before.

\section{INTRODUCTION}

Oil spill contingency planning and response is a complex and challenging cross-disciplinary activity that requires knowledge of oil weathering processes, and their effects on response methods and technologies. In the operational decision-making process, this includes the nature of the spilled oil, which undergoes changes in physical and chemical properties (oil weathering) over time, local environmental condition, spill trajectory, assessment of the impact on natural resources, and selection of the most effective clean up technologies.

Effective oil spill planning and response require access to a large amount of available data and information and the ability to rapidly process and manage this information. In addition, the decisionmaking process must integrate all of this information on a sound scientific and engineering basis to improve the effect of response countermeasures [1].

Contingency planning and spill response have been better integrated and strengthen with time. However, critical elements often missing in oil spill contingency planning and response are an understanding of oil properties, changes in these properties (weathering) over time, and incorporation of the effect on response technologies and methods. This paper focuses on oil weathering and effects on different response methods and technologies, and demonstrates delineation of windows of opportunity for selected technologies.

*Pure Appl. Chem. 71(1) (1999). An issue of special reports reviewing oil spill countermeasures. 
Marine oil spills are high profile national and international emergency response events because of their impacts to coastal environments and marine resources, wildlife, mariculture, aesthetics, recreation (tourism) and their transboundary nature. Use of inappropriate response methods and technologies may cause serious environmental damage, increased clean up costs, and potentially reduced insurance payments for spill clean up. Failure to plan for and respond to spills with the most effective-optimal technologies as a function of oil type and weathering (time) by the On Scene Coordinator (OSC) and state officials, could place the responder, federal and state governments at risk of lawsuit for negligent management from the environmental community, vessel owners and insurers. Basically the windows strategy eliminates the need for the security and expense of the shot gun approach (which covers all bases) and replaces intuition with science in the spill response decision-making process.

Given the large number of oil spills, and the lack of a scientific basis for spill response decisionmaking, the technology window-of-opportunity strategy will provide the best tool for oil spill contingency planning and response available to the local, regional, national and international community involved in spill preparedness and response. In addition, and equally as important, this strategy provides legal protection and allows all management personal to communicate the critical scientific, engineering and reasoning aspects that underlie the decision-making process to everyone involved (from operations to the public and private sectors), which in turn can be evaluated on an equal basis by all parties.

\section{WINDOWS-OF-OPPORTUNITY}

Definition: Technology Windows-of-Opportunity: The various time periods for effective utilization of marine oil spill response technologies and methodologies, in clean-up operations.

The delineation of time window of opportunity strategy integrates scientific and engineering data and information, which together provide a scientific foundation for the development of a rapid and costeffective tool for oil spill planning and spill response. It optimizes environmental and cost benefits by the selection and use of different oil spill response technologies and methodologies. The strategy integrates the following data sets: (i) dynamic oil weathering data for selected oils, (ii) actual environmental data, (iii) dynamic performance data, (iv) spill trajectory, and (v) mass balance of spilled oil.

The dynamic oil weathering and technology performance data are derived from scientific and engineering laboratory, mesoscale, and experimental field studies. In this approach, performance effectiveness data have been correlated to a wide range of viscosities and factors at different weathering stages of tanker transported oils into a dynamic oil weathering database to identify and estimate time periods, called 'technology windows-of-opportunity.'

Time window is a highly targeted process, in which the selection of response technologies will be more efficient, cost effective, technically correct, and environmentally sensitive and appropriate. The strategy provides scientifically and well documented reasons for planning and decision making activities that can provide decision makers with greater legal protection by providing justification for selection of 'best effort' response tools. Organizations that will benefit from windows-of-opportunity strategies are state and federal agencies, response planners, cleanup organizations (responders), insurance companies and oil transporters.

\section{Oil weathering}

The three dominant processes that cause changes in oil characteristics over time are spreading, evaporation and emulsification. They all occur progressively as an oil weathers at rates which depend on the oil composition and the prevailing wind speed and temperature. Spreading reduces oil thickness, and evaporation increases flash point, pour point density, and viscosity. The emulsification process significantly increases the viscosity of spilled oil and its density. The relationships between these factors and the changes in key properties during weathering have to be well understood as well as the influence on the effectiveness of specific response methods and technologies in order to estimate and delineate time windows-of-opportunity.

Different factors limit the response methods. The viscosity is a dominant factor for evaluation of the effectiveness of dispersants, mechanical recovery and for selection of mechanical clean up equipment. Flash point and water content have major influence on ignitability and sustained burning of oil, and 
density influences the effectiveness of oil and water separation technologies. In this paper, viscosity is used as a time reference for estimating the time window-of-opportunity for dispersants, mechanical recovery equipment and sorbents. Density is used as time reference for density differential separation of oil and water, and flash point and emulsification (water content) are used for in situ burning. Figure 1 illustrates the influence of oil weathering on response methods and technologies [2].

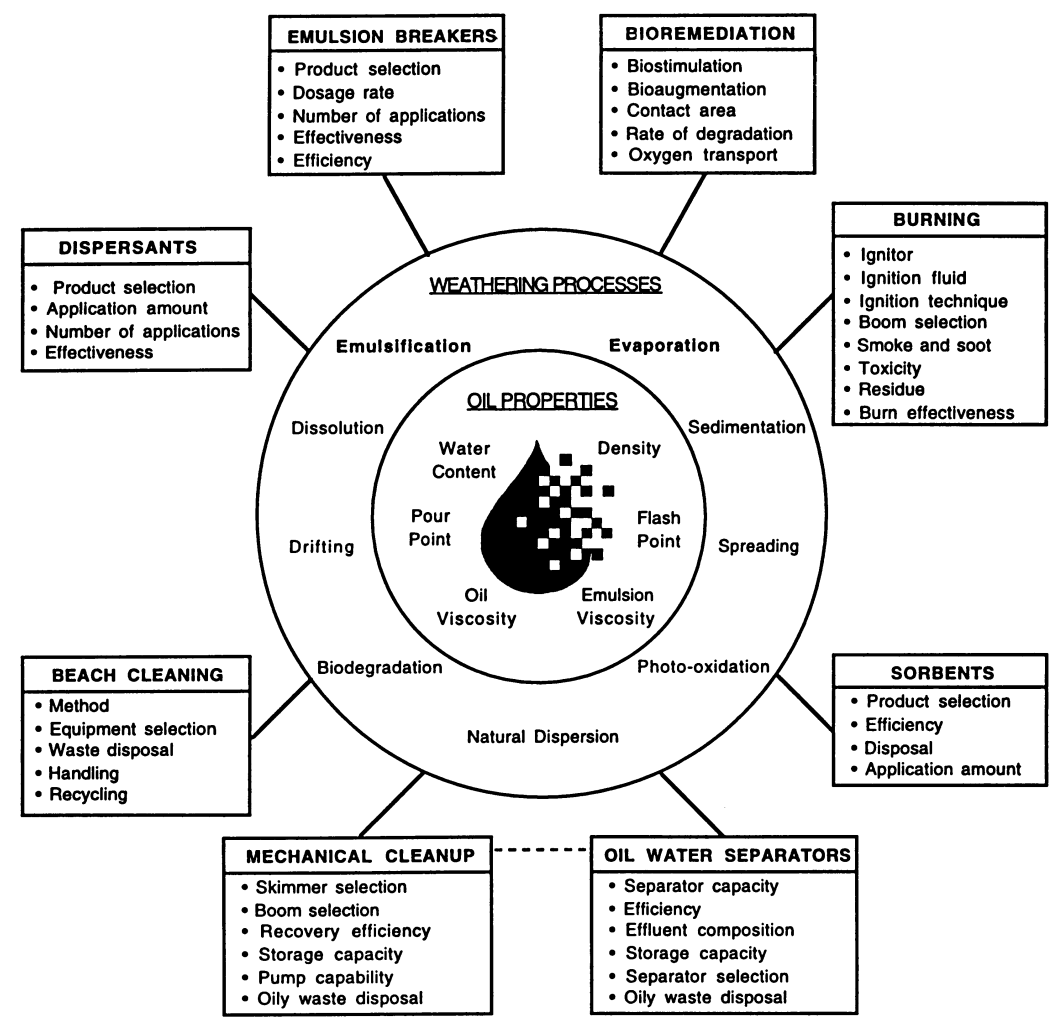

Fig. 1 Influence of oil weathering processes on the effectiveness of selected technologies for spill response.

Crude oil weathering, or the changes in oil properties and behavior at different prevailing conditions, has been extensively studied in recent years. A combination of standardized, 'step-wise' laboratory investigations, combined with numerical modeling, has enabled the changes in properties to be predicted with a high degree of accuracy for many different oil types [3]. Factors being routinely investigated in the 'step-wise' laboratory test procedure include changes of evaporative losses, flash point, pour point emulsification and viscosity of evaporated and emulsified oils. These predictions have been used to assess the applicability of response techniques such as 'time window of opportunity' for use of dispersant, and more recently for in situ burning and mechanical recovery.

Evaporation of the more volatile components and the formation of a water-in-oil emulsion during weathering occurs simultaneously during and after a spill. The rate and extent to which they proceed depends on the chemical composition of the spilled oil and prevailing environmental conditions (such as wind speed, seawater and air temperature, and sea state). Figures 2 and 3 presents IKU Oil Weathering Model predictions for the degree of evaporation and changes in emulsion viscosity as a function of time at sea for selected crude oils. Predictions have been calculated at $5 \mathrm{~m} / \mathrm{s}$ wind speed and with a seawater temperature of $15^{\circ} \mathrm{C}$.

\section{Timing is the key for success}

In determining time windows-of-opportunity, we realize that some windows may be short-lived for certain oils and environmental conditions and therefore a key to success is preplanning and rapid response [4]. If an early window is achieved, it will reduce, clean up cost, environmental impact and improve technology effectiveness. 


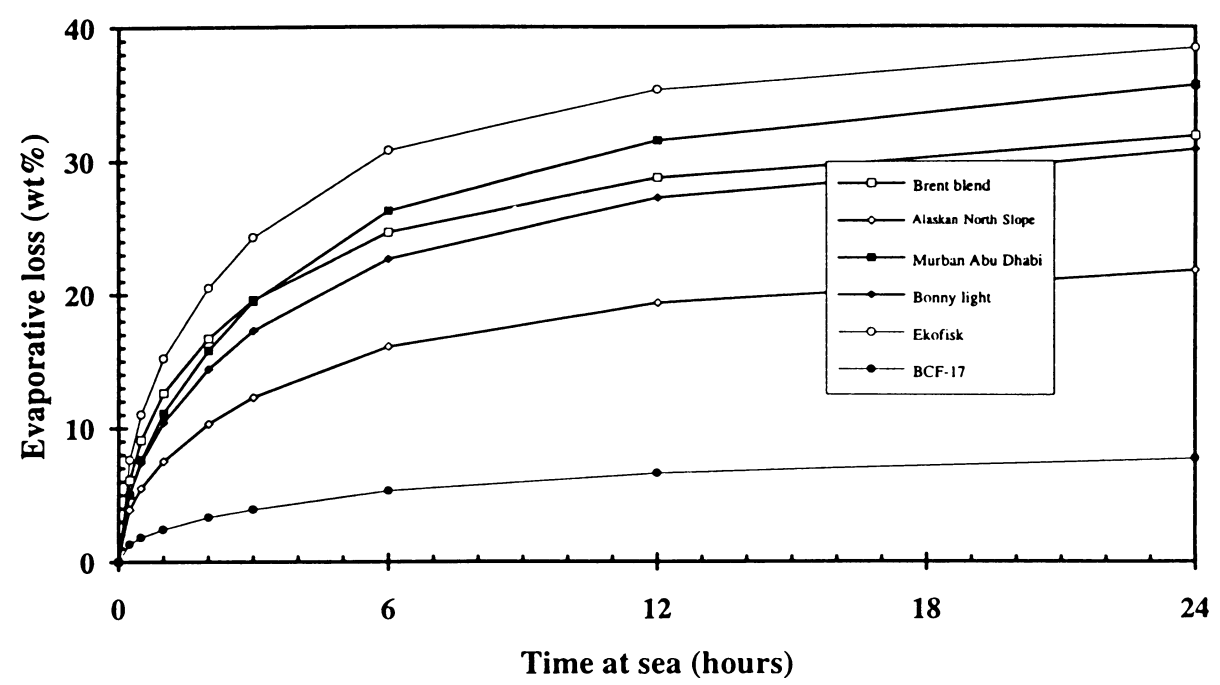

Fig. 2 IKU Oil Weathering Model predictions for the degree of evaporation as a function of time at sea for selected crude oils. Predictions have been calculated at $5 \mathrm{~m} / \mathrm{s}$ wind speed and with a seawater temperature of $15^{\circ} \mathrm{C}$.

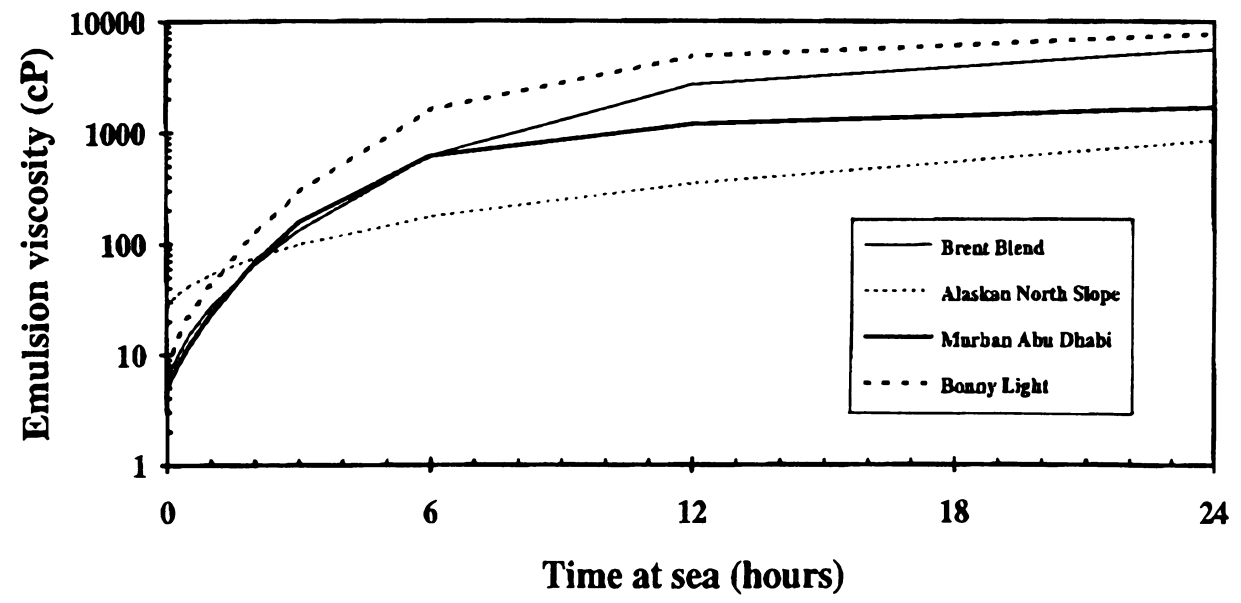

Fig. 3 IKU Oil Weathering Model predictions of viscosity of emulsions over time for selected crude oils. Predictions have been made at $5 \mathrm{~m} / \mathrm{s}$ wind speed and with a seawater temperature of $15^{\circ} \mathrm{C}$.

Three major categories of marine response (clean-up) methods are available: (i) mechanical recovery, (ii) chemical treatment, and (iii) in situ burning. Methods and technologies in each of these categories are limited by environmental conditions both operationally and as a result of the changes in oil characteristics over time. The most efficient spill response is to remove as much oil from the sea surface in the shortest time possible. Utilization of multiple response methods and technologies (mechanical, dispersant and burning) is a strategy that require a rapid and scientifically based decision-making tool and an integrated decision making process. To achieve maximum environmental and cost benefits in implementing response strategies, response tactics and technologies must be chosen to fit the time window-ofopportunity for different response methods and associated technologies.

The following sections discuss estimation of time windows-of-opportunity of selected response technologies used in marine oil spill clean-up, related to given environmental conditions, changes in oil characteristics and operational considerations.

\section{Mechanical time window}

Technologies used for mechanical clean up of spilled oil in the marine environment include; skimmers, booms, oil-water separators, sorbents, and chemical treatment agents. Of chemical agents, emulsion 
breakers are the most important [5]. The efficiency of the technologies is affected by changes in oil characteristics to various degrees dependant on the properties of the spilled oil, prevailing environmental conditions, and selection of response equipment and their principles of operation.

Many different types of skimmers have been developed over the years. They can, however, be divided into two main categories (adhesion and weir) which reflect their differences in working principles [6].

Adhesion skimmers are endless collection devices that moves continuously through the oil. The oil adheres to the rotating surface material in preference to water, and is lifted above the water level and removed by scrapers, rollers or other means of oil removal devices. Skimmers in this category includes: disc, belt, brush, mop and drum. For these skimmers it is the oil thickness on the adhesion device that in principle determine the skimmer capacity and not the thickness of the floating oil. However, the engineering design of these devices may take advantage of the floating oil thickness and increased viscosities while others do not. The effectiveness is governed by oil adhesiveness, rotational speed and the thickness of the floating oil.

The weir skimmers do not need to be in direct contact with the oil to operate. The basic principle of operation is tied to gravity forces and difference in density between oil and water [7]. A weir skimmer capacity is determined by the length and depth of the weir and pump capacity. The effectiveness is determined by cohesiveness, fluid velocity at the edge of the weir and oil thickness. Increased pump capacity and fluid velocity creates suction of water from underneath the oil slick. Table 1 presents recovery rates of brush, disc and weir skimming units at optimum rotational speed and pump capacity as a function of viscosity.

Table 1 Recovery rates of brush, disc and weir skimming units at optimum rotational speed as a function of viscosity [8]

\begin{tabular}{llll}
\hline \multicolumn{5}{c}{ Recovery rate $\left(\mathrm{m}^{3} / \mathrm{h}\right)$} \\
\cline { 2 - 4 } $\begin{array}{l}\text { Viscosity } \\
(\mathrm{cP} / \mathrm{s})\end{array}$ & $\begin{array}{l}\text { Brush }(100 \mathrm{~cm} \text { diam. } \\
61 \mathrm{~cm} \text { wide })\end{array}$ & $\begin{array}{l}\text { Disk }(38 \mathrm{~cm} \text { diam. } \\
30 \text { disks })\end{array}$ & $\begin{array}{l}\text { Weir } \\
(\text { Transrec 350) }\end{array}$ \\
\hline 1000 & 3.8 & 2.0 & $305^{*}$ \\
6000 & 7.5 & 1.25 & $235^{* *}$ \\
10000 & 10.5 & 1 & $193^{* * *}$ \\
\hline
\end{tabular}

*,**, *** Results from field trials in 1987, 1990 and 1989 respectively, using crude oil emulsions [9-11].

\section{Oil and water separation window}

Separation of free water and the water content in an emulsion can greatly improve oil storage capacity, productive skimming time, and operational effectiveness. Decrease of water content in an emulsion, by heating or use of emulsion breakers and subsequent reduction in emulsion viscosity, will improve pumpability and discharge capacity, reduce transfer and discharge time, and reduce oily waste handling, and disposal costs, facilitate disposal and enhance the potential for sale and reuse of recovered oil [12].

Separators function because of the difference in density between the oil and sea water. As an oil evaporates and form an emulsion the density increases and the density difference between the oil and seawater is being reduced. Both of these changes occur simultaneously during weathering and reduces the effectiveness of mechanical separators. In addition, crude oils and refined products cover a wide range of densities and their behavior when spilled at sea varies widely [13]. The progressive changes in oil density, formation of stable water-in-oil emulsions, and viscosity, all contribute to interfere with an effective separation. However, the emulsification process is partly or fully reversible by use of heat and/or chemical treatment with subsequent reductions in emulsion viscosity and density [14].

Separation is governed by Stokes' Law. This law assumes laminar flow, spherical droplets and ideal droplet distribution. Although these conditions are far from conditions during skimming operations, Stokes' Law can be used to illustrate the influence of changes in oil properties on separation of both oil 
and emulsion droplets in an oil-in water mixture (dispersion) and for separation of water droplets from a water-in-oil emulsion.

The two forces acting on a droplet of oil in water are the buoyancy and drag forces. The buoyancy of a droplet of oil in water, causes it to move upward at a velocity which is related to the differential density between oil and sea water. The drag force, which is a function of velocity, opposes the buoyancy force and the rise velocity reaches a terminal value when the two forces are equal [15]. Gravity separation of water from an emulsion is in direction an opposite process where water droplets are sinking in oil. Terminal velocity $(V)$, is used as a separator design criteria, and determines droplet size regimes that can be separated at a given resident time and throughput capacity.

The buoyancy force $=(\pi / 6) d^{3}\left(S_{\mathrm{w}}-S_{\mathrm{o}}\right) g$

and the drag force $($ Stokes' $)=3 \pi \mu V d$

The net separation force is the difference between the two. Terminal velocity $V$, is reached when buoyancy force equals drag force.

$(\pi / 6) d^{3}\left(S_{\mathrm{w}}-S_{\mathrm{o}}\right) g=3 \pi \mu V d$

and $V=d^{2}\left[\left(S_{\mathrm{w}}-S_{\mathrm{o}}\right) g\right] / 18 \mu$

$\mu$ is the kinematic viscosity of the continuous phase of the fluid. For separation of oil droplets and droplets of emulsion, the continuous phase is water. $\left(S_{\mathrm{w}}-S_{\mathrm{o}}\right)$ is the difference in specific gravity between sea water $S_{\mathrm{w}}$, and oil $S_{\mathrm{o}}, d$ is the droplet diameter and $g$ is the gravity force constant. The terminal velocity and effectiveness of separation can theoretically be improved by: increasing the buoyancy force, droplet diameter and replacement of gravitational force by centrifugal force, and finally by reduction of the viscosity. The window-of-opportunity for effective centrifugal separation requires a density difference of approximately $0.025 \mathrm{~g}$ per $\mathrm{mL}$. This value is used for prediction of the estimated separation window.

\section{Dispersant time windows}

Use of dispersants can sometimes be an efficient, cost effective and rapid response method provided that its used before the chemical window is closed. Dispersants accelerate natural dispersion processes and removes the oil from the surface. Tactical reasons are tied to prevention of accidental ignition and burning, protection of sensitive environmental areas and to improve removal capacity in an early phase where other resources are not available.

Weathering causes an increase in the viscosity of oil, raises its pour point, and increases the water content and the degree of stability of an emulsion. All of these changes tend to make an oil less dispersible as the viscosity of the oil or emulsion approaches its limiting value. This limiting viscosity depends on the type of spilled oil, the prevailing environmental conditions and chemical composition of the product used. The dispersant effectiveness is influenced by, viscosity of the oil and emulsion, pour point (increased viscosity), emulsion water content, and emulsion stability. An oils asphaltene and wax content are major factors that impact emulsification, chemical reactions and dispersant effectiveness. The effectiveness is time dependant and is difficult to measure under real life conditions. Samples taken immediately after spraying may not represent the final effectiveness [16]. This effectiveness is measured as the time it takes to remove a given volume of oil from the sea surface. The net increase of natural dispersion is the difference between natural and chemically enhanced dispersion.

Laboratory test results are of value for guiding the selection of an appropriate dispersant product during contingency planning and response, however, they can not be easily or directly transferred into performance data and information during spill response. Recent years of systematic field testing has, however, provided data that confirm relative effectiveness data $[17,18]$. The dispersant window can be reopened by use of dispersant and emulsion breakers in combination [19-21].

Before dispersants are included as a viable oil spill response method in contingency planning and response, the limitations of the technique must be known. It is pointless to consider the use of dispersants as a response in circumstances where it will not be feasible. Figures 4 and 5 presents effectiveness data from two different dispersant test methods (IFP and MMS) of the dispersing agent Corexit $9527^{\circledR}$, and 


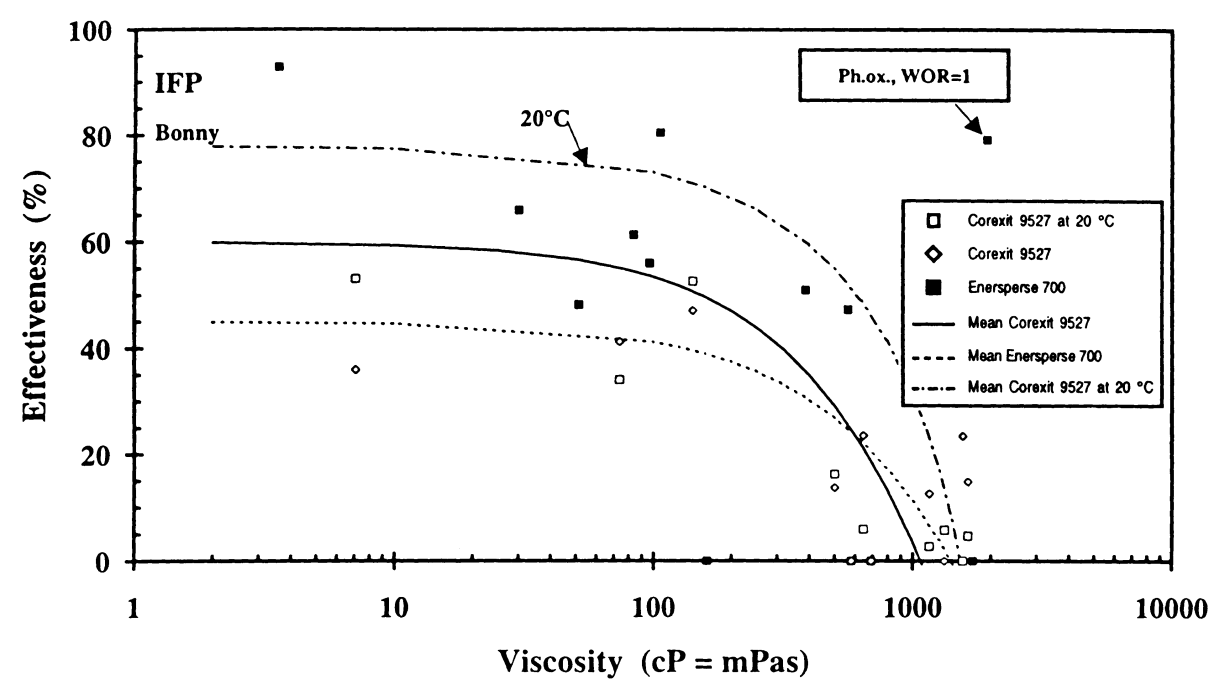

Fig. 4 Effectiveness of the dispersing agent Corexit $9527^{\circledR,}$ and Enersperse $700^{\circledR}$ vs. viscosity of water free residues (shear rate 100/s) and emulsions of different water content (shear rate 10/s) of Bonnie light Crude at a temperature $13{ }^{\circ} \mathrm{C}$. Effectiveness has been determined by the IFP test method.

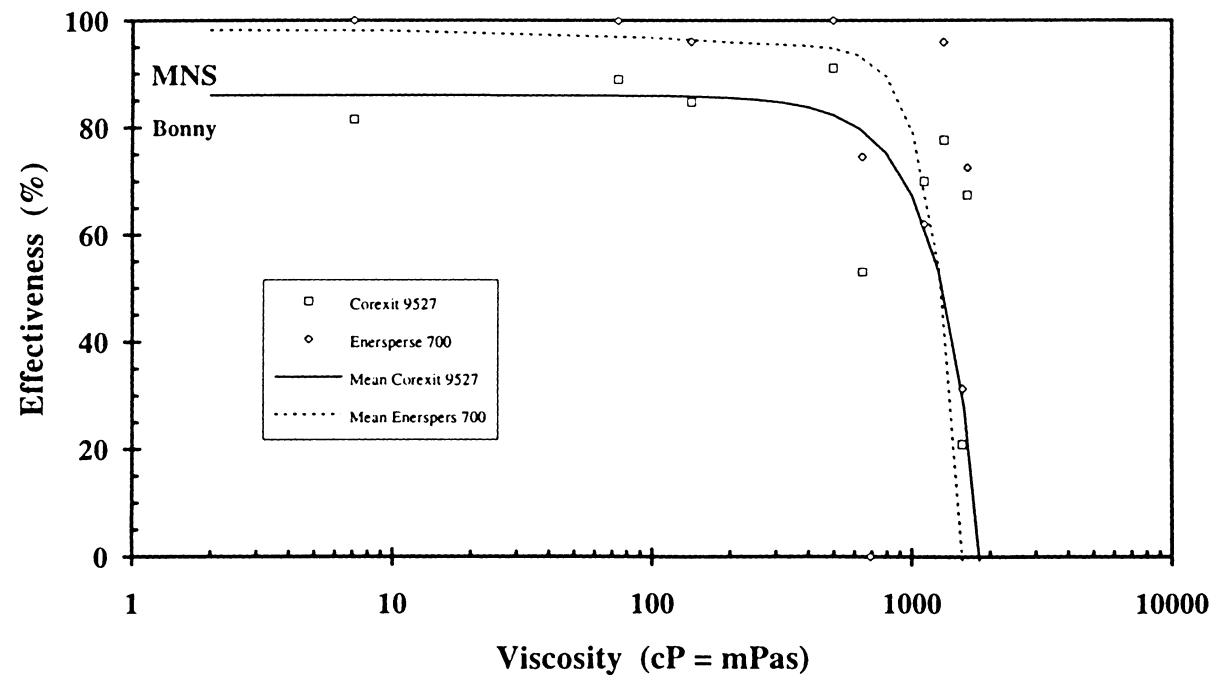

Fig. 5 Effectiveness of the dispersing agent Corexit $9527^{\circledR}$, and Enersperse $700^{\circledR}$ vs. viscosity of water free residues (shear rate 100/s) and emulsions of different water content (shear rate 10/s) of Bonnie light Crude at a temperature $13{ }^{\circ} \mathrm{C}$. Effectiveness has been determined by the MMS test method.

Enersperse $700^{\circledR}$. The effectiveness is plotted vs. viscosity of water free residues (shear rate $100 / \mathrm{s}$ ) and emulsions of different water content (shear rate 10/s) of Bonnie light Crude at a temperature $13{ }^{\circ} \mathrm{C}$. A combination of these effectiveness results and viscosity values are used for prediction of estimated dispersant time window presented in Fig. 6 .

\section{In situ burning time window}

The preliminary and valid arguments for considering in situ burning as a response measure are that it extends the options for response by providing a useful supplemental tool, while decreasing the dependency on recovered oil and water storage needs. The latter remains a limiting factor for large catastrophic spills, especially for response systems built for vessels of opportunity. In situ burning has a number of advantages compared to other oil spill response methods. It requires less specialized equipment than some other techniques, the oil is not chemically dispersed into the water column, there is 


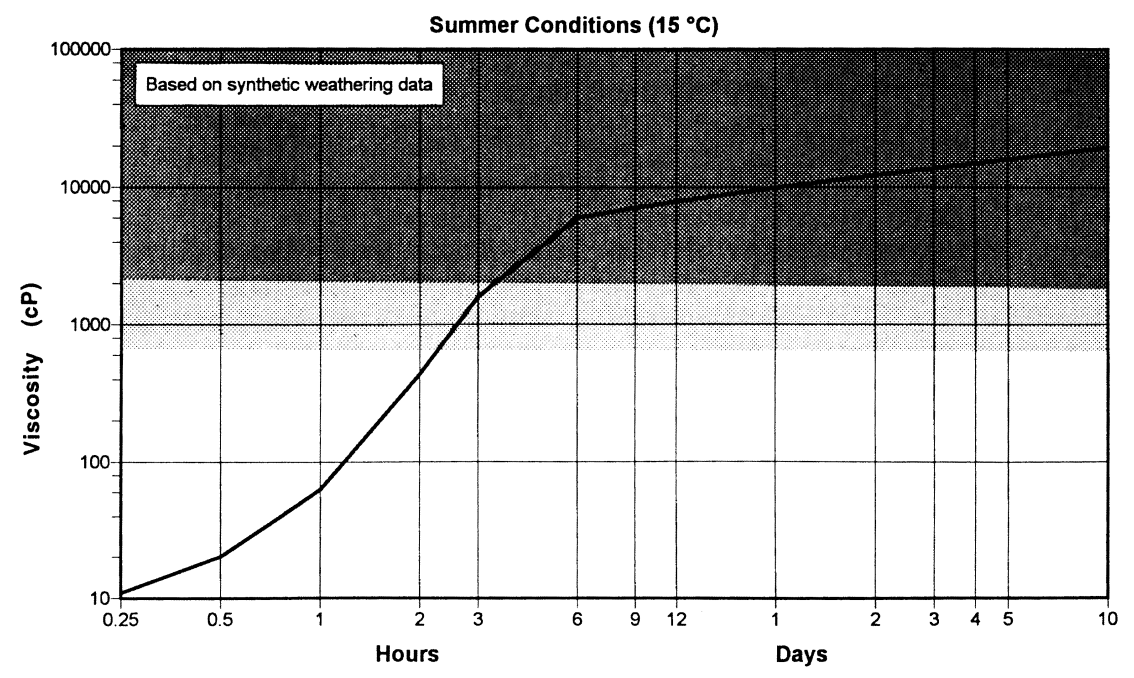

Fig. 6 IKU Oil Weathering Model estimated time window for use of Corexit $9527^{\circledR}$ on Bonnie Light emulsion. Predictions have been made at $5 \mathrm{~m} / \mathrm{s}$ wind speed and with a seawater temperature of $15^{\circ} \mathrm{C}$.

limited oil residue to be recovered and disposed of and it can rapidly deal with large quantities of spilled oil [22]. However, in situ burning, in common with all other oil spill techniques, has some disadvantages. Weathered oil (particularly emulsions) can be very difficult or impossible to ignite at sea and burning crude oil emits large volumes of black smoke.

Ignition and combustion are dependent on the flash point and release of ignitable and combustible vapor. It is the vapor released from the oil that burns, not the oil as a liquid. Thus, the mechanism for maintaining a sufficient amount of vapor for continuous burning is vital to in situ burning. The time window for ignitability and operational effectiveness of in situ burning can be assessed in the same manner as for dispersants. For ignition to occur it must be around $5 \%$ volume of hydrocarbon vapor mixed with air above the slick surface. The actual concentration depends on the rate that the flammable components evaporate from the oil. When an emulsion is being ignited, steam will be generated and dilute or bring the vapor/air mixture below the flammable/explosive range.

The proportion of the light ends in a crude oil or oil product (gasoline, marine diesel, bunker fuel oils) and the rate at which they evaporate will determine how easy it is to set fire to the oil. Evaporation of the most flammable components that boil below $150^{\circ} \mathrm{C}$ (broadly the gasoline fraction and lower) makes the oil increasingly difficult to ignite. Higher boiling point components up to about $350^{\circ} \mathrm{C}$ will burn, but require higher energy ignition sources or supplemental fuel. When a burn is well underway, the heat radiation back to the surface may be high enough to develop vaporized flammable components, provided that the oil film is thick enough and that the oil is not too emulsified.

It has been demonstrated that spills of fresh or relatively unweathered crude oil can easily be ignited and that they burn well leaving only a very small amount of residue. It is also known that spilled oil becomes difficult or impossible to ignite when the oil layer thickness drops below a critical minimum, the oil has lost a substantial proportion of its more volatile and flammable components by evaporation, and when the oil has incorporated water to form an emulsion.

The time window for ignition and sustained burning will vary, depending on environmental conditions, physical properties and chemical composition of the spilled oil. When oil is spilled on the sea the most volatile components will evaporate rapidly at a rate that depends on the slick area and thickness and the prevailing temperature (sea and air) and wind speed. Once the initially hazardous and high fire risk situation has passed, the time-window of opportunity for the use of in situ burning as an oil spill response opens, and in situ burning will become a feasible response. The time window-of-opportunity for the use of in situ burning will eventually close when the slick becomes impossible to ignite due to the oil layer thickness drops below a critical minimum [23], the oil has lost a substantial proportion of its more volatile and flammable components by evaporation, and when the oil has incorporated water to form an emulsion. All of 
these three processes (spreading, evaporation and emulsification) occur progressively as an oil weathers at rates which depend on the oil composition and the prevailing wind speed and temperature.

Some of these factors can be mitigated by the appropriate response tactic. Oil slicks that are too thin to ignite can be concentrated into a smaller area, and therefore thicker layers, by using booms. The time needed to deploy booms and the availability of suitable fire-proof booms obviously needs to be taken into account during the planning phase, if this is to be a feasible response. Some emulsions formed by crude oils will be broken by the effect of the heat from the burning oil, provided that it can be ignited in the first place, and other emulsions may be broken by the use of demulsifier chemicals, or in combination with the effect of heat from the fire. All of these tactics will extend the basic 'time window' for the use of in situ burning, but there are limits, beyond which in situ burning will not be feasible.

Thick layers of emulsion (containing up to $70 \%$ volume of water) are very difficult or impossible to ignite because the radiant heat from the igniter is consumed by evaporating the water. This prevents effective evaporation of the flammable oil components and dilutes the vapor with nonflammable water vapor. Assisted ignition will always be required for emulsified oils.

The removal effectiveness under experimental conditions has been reported from zero percentage for emulsified and weathered oils and up to $99 \%$ for fresh oils. For most crude oils, a time window for ignition and sustained burning of weathered oil using conventional ignition technology is restricted by approximately $25 \%$ evaporation and or a $50 \%$ water content.

Although the general principles and limitations of in situ burning are well known it is not always appreciated that the possibilities and limitations of in situ burning are very incident- and oil-specific. The feasibility of in situ burning can only be realistically assessed if the influences of oil composition and prevailing conditions on the 'time window of opportunity' are known. If in situ burning is to be considered as a viable removal method in contingency planning and oil spill response the limitations of the technique must be known. As for use of dispersants, it is pointless to consider the use of in situ burning as a response in circumstances where it will not be feasible. Plots of water content and flash point are presented in Fig. 7 with time for Bonnie Light crude oil. In this figure, lines have been plotted for sea temperature $\left(15^{\circ} \mathrm{C}\right)$ and for the boiling point of sea water to illustrate three categories of ignition: (i) ignitable, (ii) reduced ignitability, (iii) restricted ignitability. The reduced area of ignition can further be divided by use of water content as a limiting factor.

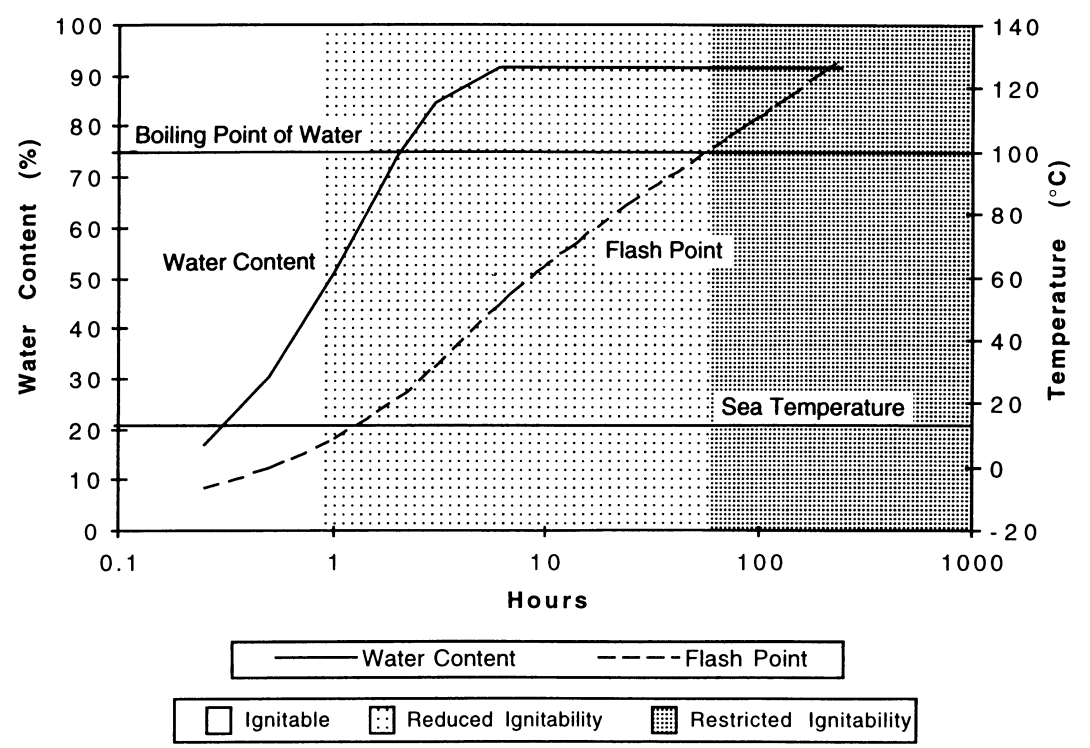

Fig. 7 Estimated time window for in situ burning of Bonnie Light crude oil using water content and flash point as function of time. Estimates have been made at $5 \mathrm{~m} / \mathrm{s}$ wind speed and sea water temperature of $15^{\circ} \mathrm{C}$ using data from the IKU Oil Weathering Model. 


\section{Windows as education and training tool}

Education and training programs are needed for all parties involved in oil spill response. Specific training programs should be developed to maximize the experience and capability to utilize the windows strategy on a local or regional basis. An ideal education program should include:

- the basic science and engineering knowledge involved in the windows strategy;

- the science and engineering knowledge involved in the design and development of equipment and technologies;

- an understanding of the changes in oil properties, physical and chemical processes involved; and

- the effects of changes in oil properties on spill response and technologies.

\section{CONCLUSIONS}

Crude oils and oil products differ greatly in physical and chemical properties, and these properties will continually change with time during a spill event as weathering (aging) occurs. These changes in oil properties with time have direct effects on oil removal and recovery capabilities, and in conjunction with environmental factors, mandate the identification and estimation of time windows-of-opportunity and selection of different response methods and technologies.

Time window is a highly targeted process, in which the selection of response technologies will be more efficient, cost effective, technically correct, and environmentally sensitive and appropriate.

Utilization of multiple response methods and technologies (mechanical, dispersant and burning) is a strategy that require a rapid and scientifically based decision-making tool and an integrated decision making process. To achieve maximum environmental and cost benefits in implementing response strategies, response tactics and technologies must be chosen to fit the time window-of-opportunity for different response methods and associated technologies.

The window strategy provides scientifically and well documented reasons for planning and decision making activities and will provide decision makers with greater legal protection by providing justification for selection of 'best effort' response tools.

Figure 8 illustrates windows for specific marine clean up technologies, selected oils, and environmental conditions.

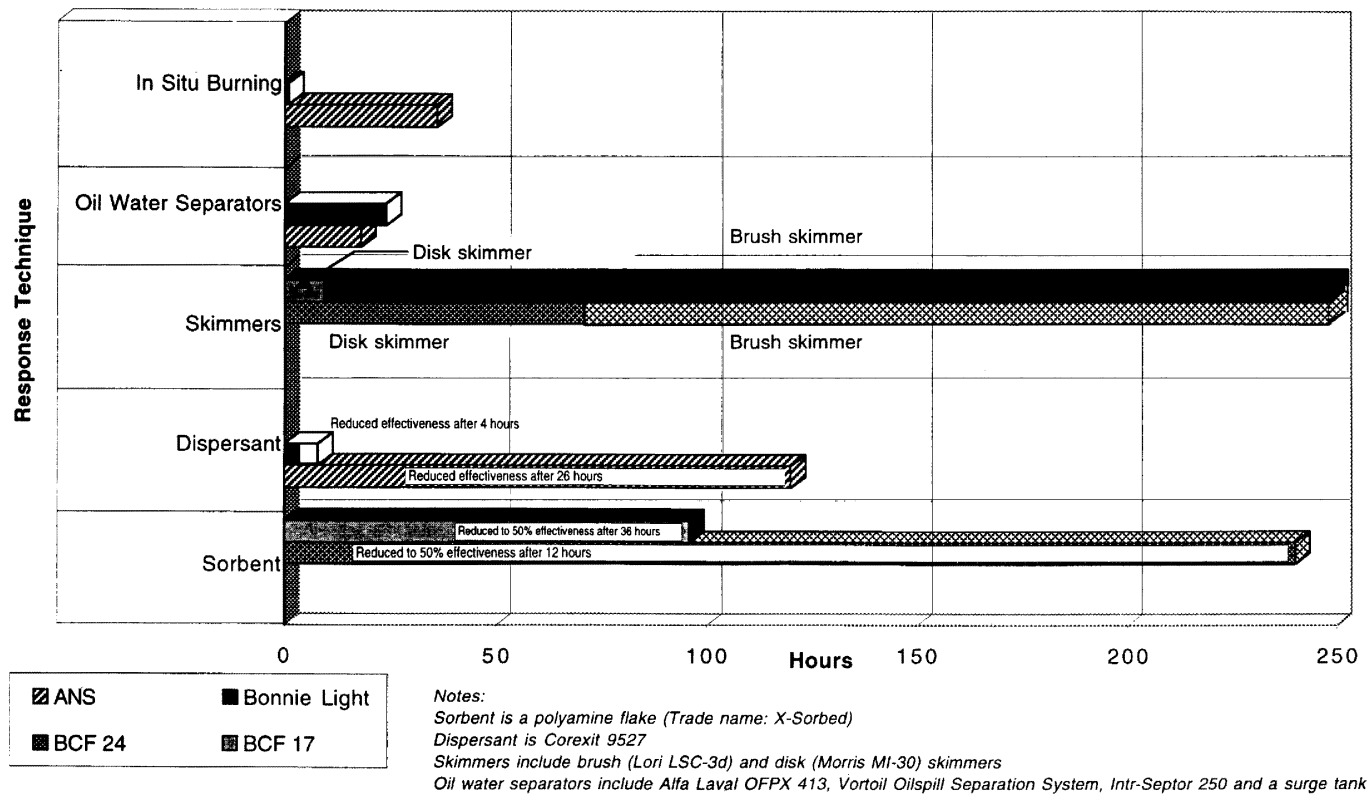

Fig. 8 Time windows for selected marine spill response techniques and oils under certain environmental conditions. The oils are Bonnie Light, Alaska North Slope, and BCF 24. The environmental conditions include wind speed of $5 \mathrm{~m} / \mathrm{s}$ and sea temperature of $15^{\circ} \mathrm{C}$. 


\section{REFERENCES}

1 A. B. Nordvik. The technology windows of opportunity for marine oil spill response as related to oil weathering and operations. Spill Sci. Technol. Bull. 2(1), 17-46 (1995a).

2 A. B. Nordvik, J. L. Simmons, M. A. Champ. Oil spill cleanup: windows of opportunity: operational decisionmaking integrates combination of factors to improve contingency planning, response worldwide. Sea Technol., October 36(9), 10-16 (1995b).

3 P. Daling, O. M. Aamo, A. Lewis, T. Strøm-Kristiansen. SINTEF/IKU Oil-weathering model: predicting oils properties at sea. In Proceedings of the 1997 International Oil Spill Conference, pp. 297-307. American Petroleum Institute, Washington, DC (1997).

4 F. R. Engelhardt. Research and development in oil spill response equipment and techniques. Paper presented at Spilcon '94. Perth, Western Australia. 3-6 October 1994 (1994).

5 A. H. Walker, D. L. Ducey, J. R. Gould Jr, A. B. Nordvik. Formation and breaking of water-in-oil emulsions. In Workshop Proc. Marine Spill Response Corporation, Washington, DC. MSRC technical Report Series 93-018 (1993).

6 A. Lewis, I. Singsaas, B. O. Johannessen, A. B. Nordvik. Key factors that control the efficiency of oil spill mechanical recovery methods. Marine Spill Response Corporation, Washington, DC. MSRC Technical Report Series, 95-038 (1995a).

7 H. Jensen, T. A. McClimans, B. O. Johannessen. Evaluation of weir skimmers without testing. In Proceedings of the 16th Arctic and Marine Oil Spill Program Technical Seminar, pp. 689-704. Environment Canada, Ottawa, Ontario, Canada (1995).

8 T. Lorentzo, R. Therrien, B. O. Johannessen Study of Viscosity and Emulsion Effects on Skimmer Performance. In Proceedings of the 18th Arctic and Marine Oil Spill Program Technical Seminar, pp. 705-729. Environment Canada, Ottawa, Ontario, Canada (1995).

9 A. B. Nordvik. Oil on water exercises: summary report. Norsk Oljevernforening For Operatørselskap (NOFO) (Norwegian Clean Seas Association for Operating Companies). Leverigsveien 32, PO Box 333, N-4001 Stavanger, Norway. 12 pp. (1987).

10 A. B. Nordvik. Summary report oil on water exercises 1989. Norsk Oljevernforening For Operatørselskap (NOFO) (Norwegian Clean Seas Association for Operating Companies). Leverigsveien 32, PO Box 333, N-4001 Stavanger, Norway. 11 pp. (1989).

11 A. B. Nordvik. Norsk oljevernforening for operatфrselskap (NOFO) Report summing up exercises 1990. NOFO (Norwegian Clean Seas Association for Operating Companies). Leverigsveien 32, PO Box 333, N-4001 Stavanger, Norway (1990).

12 A. B. Nordvik, J. L. Simmons, K. R. Bitting, A. Lewis, T. Strøm-Kristiansen. Oil-water separation in marine oil spill clean up operations. Spill Sci. Technol. Bull. 3(3), 107-122 (1997).

13 T. S. Strøm-Kristiansen, A. Lewis, P. Daling, A. B. Nordvik. Demulsification by use of heat and emulsion breaker. Phase 2. Marine Spill Response Corporation, Washington, DC. MSRC Technical Report Series, 94-012 (1994).

14 T. Strøm-Kristiansen, A. Lewis, P. S. Daling, A. B. Nordvik. Demulsification by use of heat and emulsion breaker. In Proceedings of the Eighteenth Arctic and Marine Oil Spill Program Technical Seminar, pp. 367384. Environment Canada. Ottawa, Ontario, Canada. (1995).

15 A. Fleischer. Separation of oily wastewaters the state-of-the-art. Presented at the Annual Technical Conference Canadian Institute of Marine Engineers. MARI-TECH 84, Ottawa, 25 May 1984 (1984).

16 T. Lunel. Dispersant effectiveness at sea. In Proceedings of the 1995 International Oil Spill Conference, pp. 147-155. American Petroleum Institute, Washington, DC (1995).

17 T. Lunel, L. Davis. Dispersant effectiveness in the field on fresh oils and emulsions. In Proceedings of the 19th Arctic and Marine Oil Spill Program Technical Seminar, pp. 1355-1394. Environment Canada, Ottawa, Ontario, Canada (1996).

18 A. Lewis, D. Aurand. Putting dispersants to work: overcoming obstacles. In 1997 International Oil Spill Conference Technical Report IOSC-004. American Petroleum Institute, Washington DC, pp. 157-164 (1997).

19 A. Lewis, P. S. Daling, T. Strøm-Kristiansen, A. B. Nordvik, R. J. Fiocco. Weathering and chemical dispersion of oil at sea. In 1995 International Oil Spill Conference Proceedings, pp. 157-164. American Petroleum Institute, Washington DC (1995b). 
20 M. Walker, T. Lunel. Response to oil spills using both demulsifiers and dispersants. In Proceedings of the Eighteenth Arctic and Marine Oil Spill Program Technical Seminar, pp. 537-558. Environment Canada. Ottawa, Ontario, Canada. (1995).

21 M. Walker, T. Lunel, P. Brandvik, A. Lewis. Emulsification processes at sea: forties crude oil. In Proceedings of the Eighteenth Arctic and Marine Oil Spill Program Technical Seminar, pp. 471-492. Environment Canada. Ottawa, Ontario, Canada. (1995).

22 I. A. Buist, S. L. Ross, B. K. Trudel, E. Taylor, T. G. Campbell, P. A. Westhphal, M. R. Myers, G. S. Ronzio, A. A. Allen, A. B. Nordvik. The science, technology, and effects of controlled burning of oil spills at sea. MSRC Technical Report Series, 94-013. Marine Spill Response Corporation, Washington, DC (1994).

23 C. Guénette, P. Sveum, I. Buist, T. Aunaas, L. Godal. In-situ burning of water-in-oil emulsions. MSRC Technical Report Series 94-001. MSRC, Washington, DC (1994). 